\title{
Review Article \\ Dry Powder Inhalers: A Focus on Advancements in Novel Drug Delivery Systems
}

\author{
Piyush Mehta \\ Dry Powder Inhaler Lab, Respiratory Formulations, Cipla R \& D, LBS Road, Vikhroli (W), Mumbai, Maharashtra 400079, India \\ Correspondence should be addressed to Piyush Mehta; piyu053@gmail.com
}

Received 11 August 2016; Revised 25 September 2016; Accepted 9 October 2016

Academic Editor: Ali Nokhodchi

Copyright (C) 2016 Piyush Mehta. This is an open access article distributed under the Creative Commons Attribution License, which permits unrestricted use, distribution, and reproduction in any medium, provided the original work is properly cited.

\begin{abstract}
Administration of drug molecules by inhalation route for treatment of respiratory diseases has the ability to deliver drugs, hormones, nucleic acids, steroids, proteins, and peptides, particularly to the site of action, improving the efficacy of the treatment and consequently lessening adverse effects of the treatment. Numerous inhalation delivery systems have been developed and studied to treat respiratory diseases such as asthma, COPD, and other pulmonary infections. The progress of disciplines such as biomaterials science, nanotechnology, particle engineering, molecular biology, and cell biology permits further improvement of the treatment capability. The present review analyzes modern therapeutic approaches of inhaled drugs with special emphasis on novel drug delivery system for treatment of various respiratory diseases.
\end{abstract}

\section{Introduction}

Development of inhalation technology for drug delivery has contributed immensely in treating various intrapulmonary and extrapulmonary diseases. This is supported by the lungs' unique geometry such as large surface area, thin alveolar epithelial lining, high vascularization, and avoidance of firstpass metabolism. Numerous inhalation delivery systems have been developed and studied to treat lung diseases such as asthma, COPD, and other pulmonary infections. Among them, three approaches, that is, nebulizers, pressurized metered-dose inhalers (pMDIs), and dry powder inhalers (DPI), are extensively scrutinized for the treatment of several lung diseases and pathological conditions. Each type of delivery has unique strengths and weaknesses in view of the class of drugs that can be applied, type of formulation that can be utilized, and the sum of respirable dose that can be delivered from devices. Utilization of nebulizers requires bulky compressors or a source of compressed air, while pMDIs have limitations such as sedimentation, crystal growth, and selection of appropriate propellant and they emit dosages at high velocity, which build deposition in the oropharynx most commonly where they are swallowed and enhance the risk of systemic absorption [1]. DPIs were introduced to defeat some of the weaknesses associated with nebulizers and pMDIs [2].
DPIs provide better physicochemical stability and deep lungs deposition using the patient's respiration. Additionally, they do not require cold chain storage or reconstitution of powders into solutions for nebulization $[1,2]$. Lactose monohydrate is the most commonly used excipient (i.e., carrier) in DPI formulations. Mixtures of the lactose with drug are commonly described as ordered or interactive mixtures, which are simpler to handle during the manufacturing than micronized drug alone. The drug particles should loosely adhere to the lactose (carrier) particles and, during inhalation in the turbulent air stream which is produced, the drug particles detach from the lactose (carrier) particles and are made accessible for deposition into the lungs. The larger carrier particles normally impact the oropharyngeal region. The carrier also offers mass to the DPIs, which enhances the handling, dispensing, and actuation of the micronized drug, which is of actual significance for low dose DPIs such as steroids (typical dose per actuation: $50 \mu \mathrm{g}$ to $500 \mu \mathrm{g}$ ) $[3,4]$. In order to confirm effective delivery of drug, it is crucial that adhesive forces between the drug and carrier are not so strong that separation from the carrier is prohibited. The equilibrium between adhesive and cohesive forces should be in tune to confirm sufficient adhesion between drug and carrier so as to provide a stable formulation (homogeneous blend with good content uniformity) but with adequate detachment 
of drug from carrier on inhalation. It has been recognized that the efficiency of a DPI formulation is greatly dependent on the particle size distribution, fine-lactose content, lactose source, the inhalation flow rate, and dispersion capacity of the respective DPI device [3].

With the growth of disciplines such as biomaterials and materials science, nanotechnology, particle engineering, molecular biology, and cell biology have gotten rapid development in field of novel drug delivery systems (NDDS). These NDDS in the field of western medicine have been extensively studied and applied clinically. The development of NDDS based DPIs has the potential to overcome issues associated with carrier as a critical component of the formulation. Moreover, they are expected to accomplish various key requisites like aerosolization properties of the formulation, physicochemical characteristics of powder, stability, biocompatibility, and biodegradation without any adverse effect. Conservative delivery systems are unable to meet these demands. Developing various novel drug delivery systems, for instance, liposomes, solid lipid nanoparticles, polymeric nanoparticles, nanoaggregates, nanocomposites, polymeric microparticles, and microspheres, has offered a number of advantages for traditional dry powder inhaler, including physical and chemical stability, flow properties, dispersion, tissue distribution, and bioavailability. Several potential DPIs have been successfully delivered using NDDS approach. Therefore, in this article, an attempt has been made to touch upon different aspects related to the development of novel drug delivery systems including their impact on drug dispersion and disposition and other physicochemical properties are discussed in detail. This review offers a perspective on current reported studies to modify pulmonary deliveries for its better functioning.

\section{Novel Drug Delivery System for DPI}

\subsection{Lipid Vesicles}

2.1.1. Liposomes. Liposomes are typically self-enclosed small spherical arrangement composed of a single bilayer lipid membrane (unilamellar liposomes) or several bilayer lipid membranes (multilamellar liposomes) with a size range of 50 to $1000 \mathrm{~nm}$. They have various functions ranging from drug delivery to food carrier [5]. They help improve the solubility, bioavailability, in vitro and in vivo stability, targeted delivery, and sustained release and, moreover, have ability to enhance the intracellular uptake of drug components and biodistribution pattern with protecting the encapsulated agent from the destructive action of the external environment [6]. Literature showed that numerous inhaled liposomal products are in various stages of clinical trials [7]. Site-specificity, biodegradability, biocompatibility, good safety profile, and potential to enclose both hydrophobic and hydrophilic particles are the prime reasons to choose liposomes in pharmaceutical industries [8].

Liposomes are widely scrutinized as vehicle for the dry powder inhalation delivery of various drugs for treatment of several diseases and pathological conditions. They can be easily aerosolized and provide prolonged retention of carriers and drugs in the respiratory track [22]. Liposomes seem mostly suitable for delivery of drugs to the lungs as they can be prepared from substances endogenous to the lung as elements of lung surfactant. Lung surfactant is a complex mixture, of which about $85 \%$ is phospholipid, generally dipalmitoyl phosphatidylcholine (DPPC), with phosphatidylglycerol as the next most widespread phospholipid. Surfactant is also composed of cholesterol and two groups of nonserum proteins which are believed to be important in the adsorption, spreading, and reutilization of surfactant. The mechanisms for the clearance and reutilization of lung surfactant are likely to be of major importance in determining the fate of liposomes deposited in the alveoli. The rate and extent of pulmonary uptake of liposomes are a function of their composition; significantly faster rates occur when liposomes contain phosphatidylglycerol [23]. In most cases, no considerable undesirable side effects were observed after the application of neutral or slightly negatively charged liposomes, though cationic liposomes were found to be toxic to human cells and potentially can introduce genetic aberrations [24]. Besides, adverse side effects of cationic liposomes considerably increased with an increase of positive charge of the particles. Still, because cationic liposomes normally are used for the formation of almost neutral complexes with negatively charged nucleic acids, such modification of cationic carriers usually prevents adverse effects on the cells [24]. Various investigations on liposomal formulations of inhaled drugs are listed in Table 1.

2.1.2. Proliposomes. Proliposomes are described as dry, freeflowing microparticles with a dispersed system which can easily form a liposomal vesicle when in contact with water or biological fluids. Simply, powdered drugs are prepared by the adsorption of phospholipids and drug moiety onto the microporous matrix of carrier particles [37]. Compared with conventional liposomes, proliposomes display more advantages in stability, drug release, and solubility [21]. Therefore, proliposomes would be a potential medium to enhance oral absorption of hydrophobic drugs. The primary mechanism allowing proliposomes to improve oral absorption might be partially explained by the presence of bile salts, which can interact with phospholipids in the gastrointestinal tract to construct mixed micelles for medium to augment the solubility of hydrophobic drugs [38]. Various investigations on proliposomal formulations of inhaled drugs are listed in Table 1.

2.1.3. Lipospheres. Lipospheres are also typically selfenclosed small spherical arrangement composed of water dispersible solid microparticles of particle size between 0.2 and $100 \mu \mathrm{m}$ in diameter and a solid hydrophobic fat core stabilized by one monolayer of phospholipid molecules embedded in their surface. Due to their solid lipid matrix, controlled release from these carriers is achievable which is essential to provide the drug over a prolonged period of time with improved bioavailability and physicochemical stability [42].

Cyclosporine A (CsA) lipospheres based DPI was formulated using dipalmitoylphosphatidylcholine (DPPC) and dipalmitoylphosphatidylglycerol (DPPG) $(75: 25)$ phospholipids by spray drying method. Aerosol dispersion pattern 


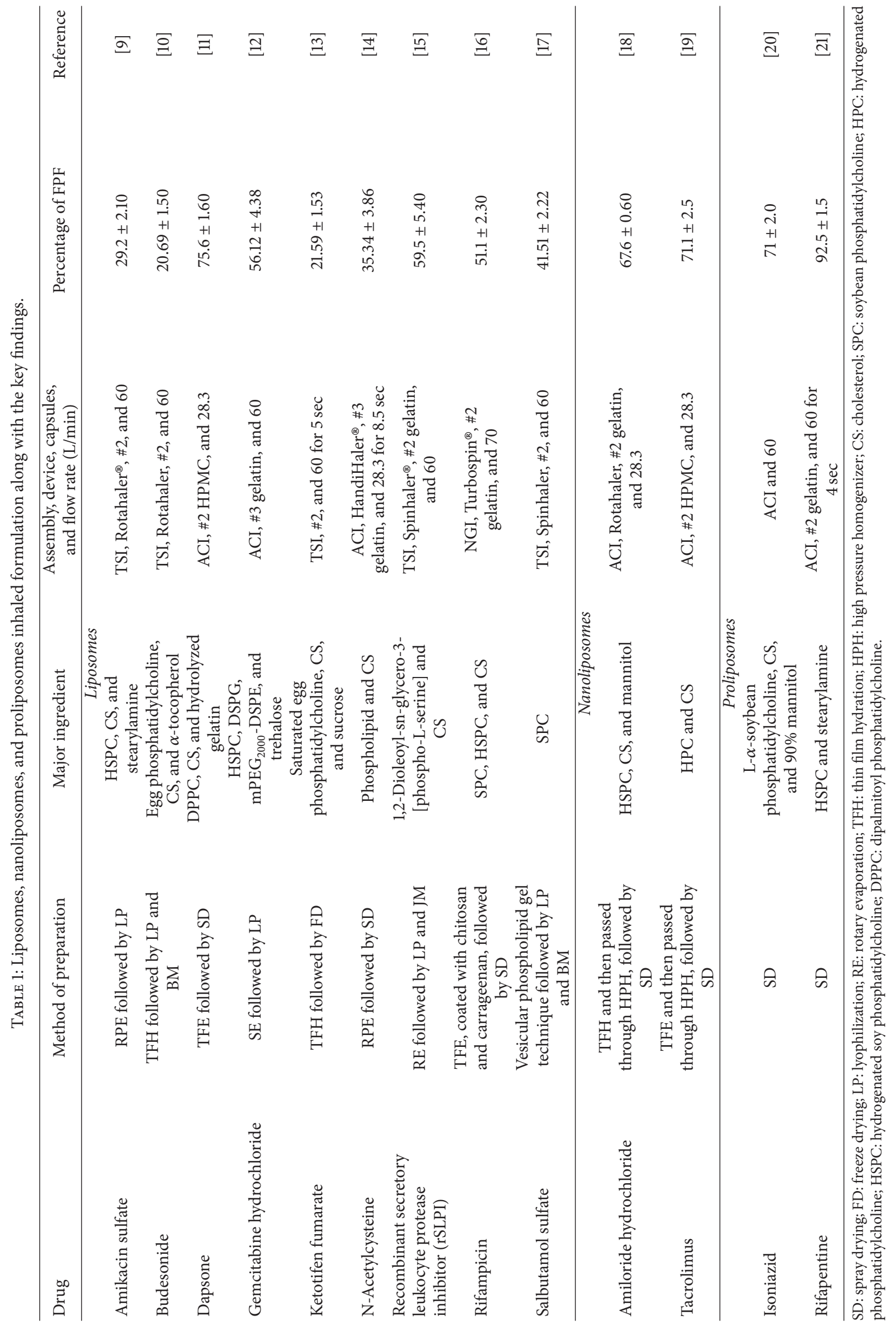


was determined using a next generation impactor (NGI) with a HandiHaler device at $60 \mathrm{~L} / \mathrm{min}$ using \#3 HPMC capsules. The percentage of fine particle fraction (FPF), mass median aerodynamic diameter (MMAD), and geometric standard deviation (GSD) was found to be $52.99 \pm 4.12 \%$, $2.79 \pm 0.47 \mu \mathrm{m}$, and $1.85 \pm 0.05$, respectively. In summary, compared to drug alone prepared co-SD CsA, DPPC/DPPG lipospheres displayed better physicochemical properties and aerosol dispersion with very low residual water content [63]. Singh et al. investigated the rifampicin loaded phospholipid lipospheres containing sulfphobutyl ether, $\beta$-cyclodextrin, and Vit. $C$ formulated using spray drying technique. Prepared amorphous lipospheres showed spherical morphology with the size range of $1-5 \mu \mathrm{m}$. Aerosol dispersion pattern was concluded using Andersen cascade impactor (ACI) with device operating at $28.3 \mathrm{~L} / \mathrm{min}$ using \#3 HPMC capsules. The FPF and emitted dose (ED) were found to be $52.99 \pm$ $4.12 \%$ and $85.40 \pm 1.04 \%$, respectively. Moreover, prepared lipospheres exhibited approximately $\sim 2$-fold improvement in antimycobacterial activity over $\mathrm{MTB}_{37} \mathrm{Rv}$ strain compared to drug alone. Improvement in antimycobacterial activity may be attributed to the cyclodextrin-cholesterol matrix structure [64].

2.1.4. Lipid-Coated Particles. Liposomes, proliposomes, and lipospheres have been the platform of choice for pulmonary drug delivery applications over the past decade. However, extensive investigation has revealed their restrictions as drug delivery carriers. They have limitations. For instance, phospholipid may sometimes undergo oxidation and hydrolysis like reaction, short half-life, and poor mechanical stability due to leakage and fusion of the formulation [70]. To overcome these limitations, a hybrid class of lipid-coated particles has received good attention in recent years. Lipid coating offers better stability and higher encapsulation efficiency than liposomes. The existence of a low lipid coating level permits the preparation of powders with few excipients, thereby delivering more drug to the lungs. Additionally, the hydrophobic nature of neutral lipids (cholesterol) decreases the absorption of the ubiquitous vapor, leading to lessening the aggregation and the adhesion of particles [71].

Tobramycin lipid-coated particles were prepared using mixtures of cholesterol and phospholipids $(75: 25)$ by spray drying technique. Developed lipid-coated particles showed small, smooth surface properties and good flowability with a mean size of about $1-2 \mathrm{~mm}$. Aerosol dispersion pattern was determined using a multistage liquid impinger (MSLI) with a Cyclohaler ${ }^{\circledR}$ device at $100 \mathrm{~L} / \mathrm{min}$ for $2.4 \mathrm{~s}$ using \#3 HPMC capsules containing $15 \mathrm{mg}$ of tobramycin lipid-coated particles. The FPF of prepared lipid-coated particles was found to be $68 \%$ with approximately $\sim 1.5$-fold improvement in FPF compared to uncoated micronized tobramycin particles. Developed lipid-coated tobramycin DPI formulations required very low amount of excipient and produce better lung deposition. These formulations are mostly useful for drugs that are active at relatively high doses, for example, antibiotics, since they allow the delivery of a high concentration of antibiotic directly to the site of action while minimizing systemic exposure [71].
2.2. Nanoparticulate System. Nanoparticles are solid, colloidal particles comprising macromolecular materials that differ in size from $10 \mathrm{~nm}$ to $1000 \mathrm{~nm}$ in which the drug moiety is dissolved, encapsulated, and entrapped and/or to which the drug moiety is adsorbed, embedded, or attached, which can be administered in fluid form with a liquid carrier. A wide variety of delivery systems includes nanoparticles, polymeric nanoparticles, polymeric micelles, solid lipid nanoparticles (SLNs), nanostructured lipid carriers (NLCs), nanocapsules, nanospheres, nanoemulsion, and many more. They have the capacity to modulate both the pharmacokinetic and pharmacodynamic properties of drugs, thereby improving their therapeutic index. Nanoparticles help modify the biodistribution, in vivo stability, bioavailability, and penetration through biological barriers. Moreover, they also provide controlled and targeted drug release [81-83].

Inhalable nanoparticles are advantageous for the objective of improving the solubility, dissolution profiles, and pharmacokinetic profile and reducing premature mucociliary clearance of hydrophobic drugs [84]. The size, shape, and composition of nanoparticles are key features which determine their percentage retention and targeting properties [22]. Inhaled nanoparticles could be easily exhaled during administration due to their small diameter $(\ll 1 \mu \mathrm{m})$ and low inertia. Nanonization often conveys an enormous increase in Gibb's free energy due to the increase in surface area. Moreover, these particles have tendency to grow due to Ostwald ripening and can suffer from uninhibited agglomeration [85-88]. This issue has been resolved by transforming nanoparticles into inhalable microaggregates via numerous techniques like spray drying and spray freeze drying or with leucine, mannitol, and PVA as matrix components $[89,90]$. Spray freeze dried microaggregates exhibited superior aerosolization performance compared to those produced by spray drying and this was credited to the porous structure and low density of the particles [91-93]. Various investigations on nanoparticulate formulations of inhaled drugs are listed in Table 2.

\subsubsection{Solid Lipid Nanoparticles and Nanostructured Lipid} Carriers. SLNs are the first generation of lipid nanoparticles. They are colloidal carriers made up of physiologically tolerated lipids components that remain solid at body and room temperature with mean diameter of 40 to $1000 \mathrm{~nm}$ [94]. Generally, SLNs are made up of $0.1-30 \%$ (w/w) lipid dispersed in an aqueous solution of $0.5-5 \%(w / w)$ surfactant as stabilizing agent. SLNs provide different advantage like physicochemical stability, protection of the incorporated drug from degradation, prolonged/sustained release profile with pseudo-zero-order kinetics, and low cytotoxicity, if well tolerated excipients are used $[95,96]$. SLNs have disadvantages like low drug loading capacity and drug expulsion during storage. Drug expulsion takes place when the low ordered lipid modification of the particle matrix after manufacturing switches to the highly ordered $\beta$-modification during storage. The $\beta$-modification is characterized by a perfect crystal lattice with few imperfections and hence little room for drug accommodation. To defeat these SLNs related issues, the second generation of lipid nanoparticles, nanostructured lipid carriers, was developed [97]. NLCs are a delivery system 


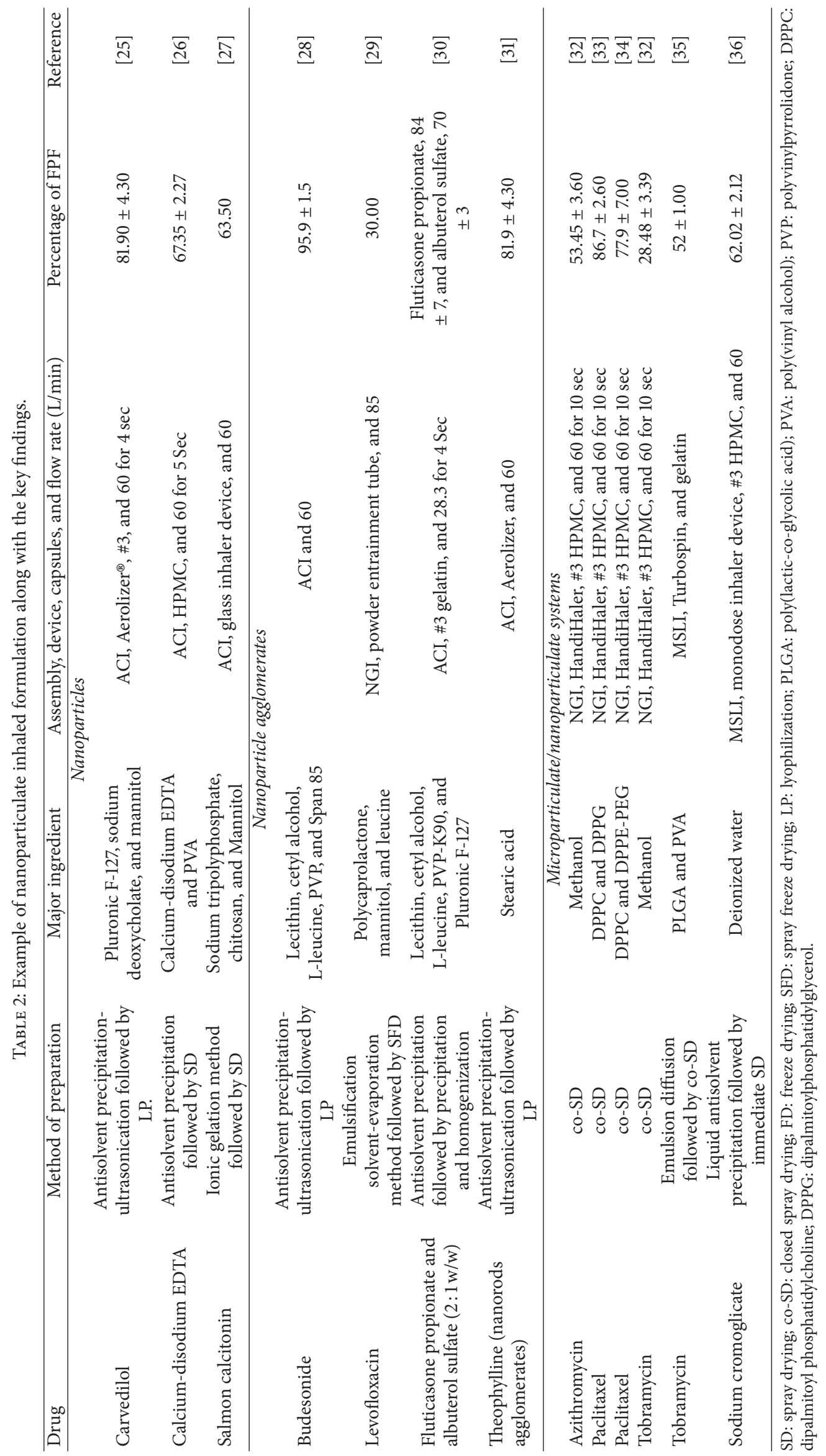


in which partial-crystallized lipid particles with mean particle size $\leq 100 \mathrm{~nm}$ are dispersed in an aqueous phase containing emulsifier(s). NLCs have a solid lipid matrix at room and body temperature which is composed of a mixture of a solid lipid and oil, preferable in a ratio of $70: 30$ up to a ratio of $99.9: 0.1$. Through mixing different kinds of lipids, a less ordered lipid matrix with high drug loading capacity for drugs is achieved [95].

Moreover, due to their controlled size, nanoparticles can be easily aerosolized into droplets with aerodynamically suitable properties, which permits adequate deep lung deposition of a drug. Furthermore, particle adhesion, accumulation, and retention in the pulmonary region as well as controlled release properties of SLNs and NLCs may lead to improved and sustained therapeutic outcomes, resulting in a longer dosing interval and better patient compliance [95, 98]. Considering these unique functionalities, researchers have developed several SLNs and NLCs based DPI formulations to enhance the therapeutic efficacy of inhaled drug molecules (Table 3).

2.3. Microparticulate System. The expression "microparticle" in drug delivery is usually designated to a particle with one or several micrometers in dimension. Based upon the method of preparation, the drug is entrapped, encapsulated, or simply dissolved to the microparticle template. Microparticle matrix contains many materials like polymers, ceramics, metals, and glass. This system is believed and accepted as a steady means to deliver the drugs to the target site with specificity [57]. Various delivery approaches involve microparticles, microspheres, solid lipid microparticles, polymeric microparticles [58, 99], surface coated microparticles [61], and so forth. In clinical practices, microparticles appreciably influence retention in the lungs and targeting properties of therapeutic agent, apart from the fact that active targeting microparticles also offer numerous advantages like masking, facilitation of handling, controlled dissolution profile, and protection [100]. Various investigations on microparticulate formulations of inhaled drugs are listed in Table 4.

2.3.1. Microsphere. Microspheres are microparticles of spherical shape without membrane or any distinct outer layer. They are small solid spherical particles made up of various natural and synthetic materials with mean diameter of 1 to $1000 \mu \mathrm{m}$. Microspheres may release drug at controlled rates for long periods of time. Microspheres are ideal vehicles for many controlled delivery applications due to their ability to encapsulate a variety of drugs, biocompatibility, high bioavailability, and prolonged/sustained drug release characteristics. Such techniques also offer various benefits over conventional methods of drug delivery, including protection of fragile drugs, tailoring of drug release rates, and increased patient comfort and compliance. Polymethyl methacrylate, acrolein, glycidyl methacrylate, lactides, poly(alkyl cyanoacrylate), polyanhydrides, poly(D, L-lactic-co-glycolic acid) and chitosan, poly(acryl) dextran, poly(acryl) starch, carrageenan, and gelatin are the commonly used polymeric agents for microspheres synthesis [101]. Microspheres based DPI formulations are listed in Table 5.
2.3.2. Mucoadhesive Microparticles. Mucoadhesion can be defined as the interaction of molecules with the mucous layer (biological tissue) in order to adhere to each other. Mucoadhesion techniques have received a good attention, in drug delivery system, due to their two prime requisites. First, they increase mean residence time of therapeutic agent. Second, they uphold a high concentration gradient of drug molecule across the epithelium. Mucoadhesion occurs via several mechanisms such as chain interlocking, diffusion, and chemical reaction (hydrogen bonding) [102]. These mucoadhesive agents are usually high molecular weight polymers which can interact with the mucin layer of the respiratory epithelium due to hydrogen bonding and electrostatic, hydrophobic, or van der Waals interactions. Chitosan, carbomer, poly(lactic acid), poly(D,L-lactic-co-glycolic acid), hydroxypropyl cellulose, and sodium carboxy methylcellulose are the commonly used mucoadhesive agents for inhalation drug delivery. The incorporation of therapeutic agents into these polymeric matrices regulates the drug pharmacokinetics by improving lung mean residence time. Even though the idea of mucoadhesion at the upper respiratory tract has been broadly studied, application to the lower respiratory tract has not been explored [103].

M. Mishra and B. Mishra formulated the doxycycline hyclate mucoadhesive microparticles using sodium carboxy methyl cellulose as mucoadhesive agents by spray drying technique. Developed microparticles showed moderately dimpled but spherical shape $(1-5 \mu \mathrm{m})$ with $56.27 \%$ yield, 83.74 $\pm 2.31 \%$ encapsulation efficiency, and $4.16 \pm 0.52 \%$ water content. Aerosol dispersion was examined using ACI with monodose inhaler device at flow rate of $60 \mathrm{~L} / \mathrm{min}$ for $4 \mathrm{sec}$ using \#2 gelatin capsules. ACI analysis suggested good dispersion and deposition with the FPF, ED, and MMAD of 55.5 $\pm 4.2 \%, 80.2 \pm 0.4$, and $4.56 \pm 0.10$, respectively. Drug release from these mucoadhesive microparticles showed biphasic Fickian type of diffusion. Moreover, prepared microparticles exhibited good output in MTT assay on H1299 mammalian alveolar cells. Doxycycline hyclate containing sodium carboxy methyl cellulose mucoadhesive microparticles would be helpful dosage form for clinical treatment of respiratory infections with minimal adverse side effects [103]. Mucoadhesive beclomethasone dipropionate (BDP) microspheres for powder inhalation were formulated using hydroxypropyl cellulose (HPC) mucoadhesive polymer (1:4) by spray drying technique. This resulted in amorphous (aBDP/HPC) and crystalline (cBDP/HPC) microspheres with mean particle size of $2.5-2.9 \mu \mathrm{m}$. BDP's aqueous solubility was improved 25 times for aBDP/HPC, compared to cBDP/HPC. In antigen-induced asthmatic Guinea pigs, aBDP/HPC showed quick BDP absorption from the lungs ( $\geq 95 \%$ absorption for $180 \mathrm{~min}$ ) with a greater metabolite (B17MP) formation, compared to $\mathrm{CBDP} / \mathrm{HPC}$, mainly due to the improved dissolution of aBDP/HPC. In contrast, $86.0 \%$ of BDP remained at 180 min following cBDP/HPC administration, indicating the prolonged retention of BDP in the lungs by virtue of poor dissolution (release) and delayed mucociliary clearance. cBDP $(1.37 \mathrm{mg} / \mathrm{kg})$ alone considerably inhibited eosinophil infiltration into the lungs of antigen sensitized and challenged Guinea pigs for only $1-6 \mathrm{~h}$ and at much lower drug dosage 


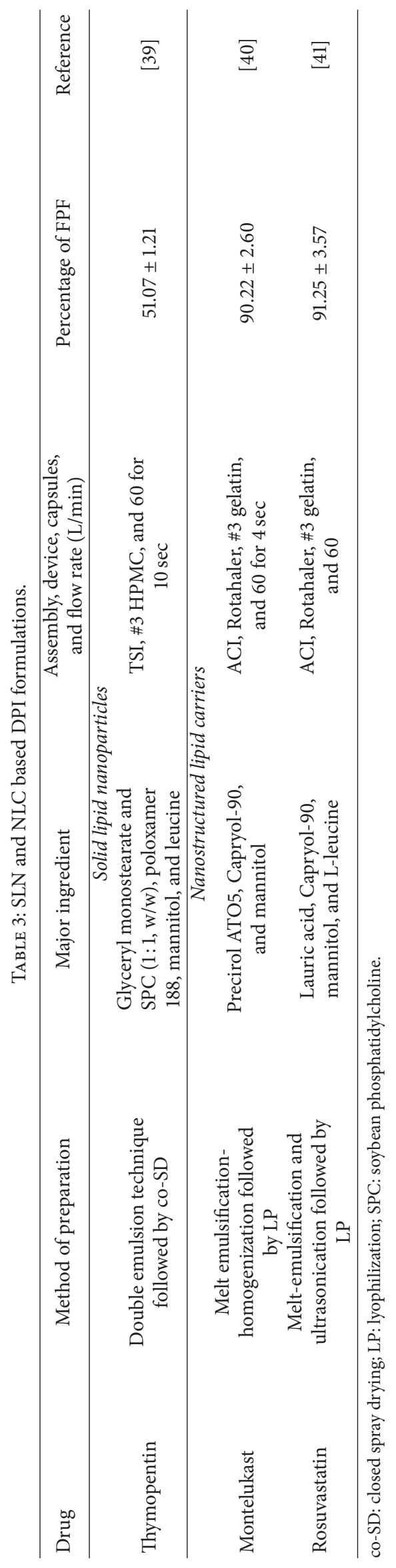




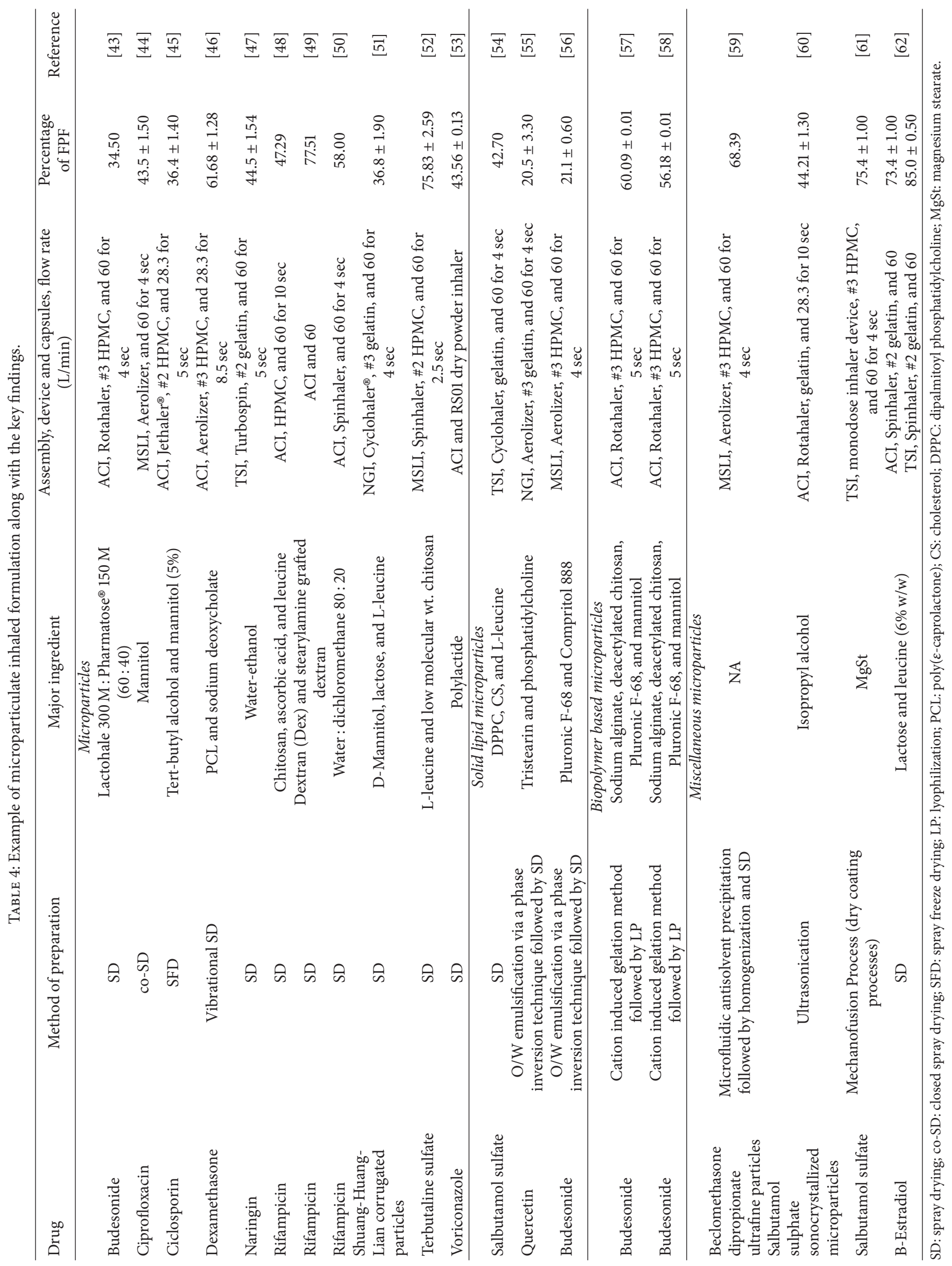




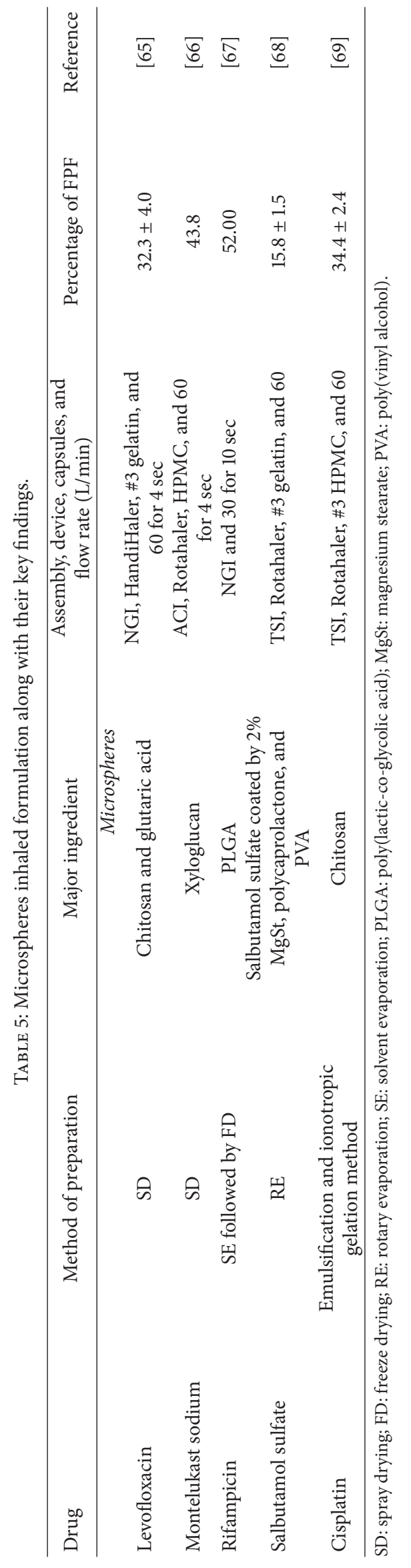


of cBDP/HPC $(0.25 \mathrm{mg} / \mathrm{kg})$ was capable of maintaining such inhibitory effects for $24 \mathrm{~h}$ following administration. The prolonged lung retention of BDP by the use of the $\mathrm{CBDP} / \mathrm{HPC}$ microspheres was credited to prolonging its pharmacological duration without requiring increased drug dosage [104].

2.4. Solid Dispersions. Solid dispersions are one of the known approaches to improve drug solubility and release profile of poorly water-soluble drugs. It is a molecular mixture of drug in hydrophilic polymer wherein the drug physicochemical characteristics are regulated by the polymer properties [105]. Here, the drug dissolution profile may be enhanced by reducing the drug particle size to nearly a molecular level and by transforming the drug crystalline state to create a complete or partially amorphous state, both of which may improve drug solubility and bioavailability [106]. Commonly used polymers in formulation of solid dispersions are cyclodextrin, hydroxy propyl methylcellulose, hydroxy propyl cellulose, ethyl cellulose, silica, povidone, starch, and polyethylene glycols [107]. Solid dispersions act as a flexible platform for novel drug delivery systems.

Itraconazole (ITZ) SD based DPI was formulated using polymeric surfactant, that is, TPGS and hydrophilic agent, and mannitol by spray drying method. Prepared ITZ-SD-DPI compared with ITZ-SD-DPI without TPGS and bulk ITZ. ITZ-SD produced an improved dissolution rate and greater saturation solubility than bulk ITZ. The use of a polymeric surfactant (TPGS) was helpful in terms of solubility and dissolution profile but it also reduced FPF $(47 \pm 2 \%$ to $37.2 \pm 0.4 \%)$. Additionally, device and capsule retention of ITZ-SD-DPI was significantly reduced when TPSG was used into the formulations. This may be due to lubricant effect of TPGS which improved device and capsule emptying by reducing the surface interaction and greater particle cohesion. Mannitol solid dispersions with optimized quantity polymeric surfactant may provide an effective platform for poorly soluble active ingredients DPI [108]. Cyclosporine A (CsA) amorphous solid dispersion was prepared by using wet-milling technique (WM/CsA) and jet milled with coarse lactose (Respitose SV003) to obtain desired aerodynamic particle size. WM/CsA-DPI exhibits the better dissolution profile as compared to pure CsA. Aerosol dispersion was examined using ACI with Jethaler device operating at a flow rate of $28.3 \mathrm{~L} / \mathrm{min}$. ACI analysis recommended good dispersion and deposition in the respiratory organs with the FPF and ED of 54 and 96\%, respectively. Moreover, intratracheal administration of WM/CsA (100 $\mu \mathrm{g}$ CsA) in experimental animals led to 85 and $71 \%$ reduction of granulocyte recruitment in lung tissues and bronchoalveolar lavage fluids. In comparison to a commercially available CsA oral formulation, WM/CsA showed $10^{2}$-fold reduction in AUC and Cmax values of plasma CsA at toxic concentration $(10 \mathrm{mg} / \mathrm{kg})$. WM/CsADPI would be effective dosage form for clinical treatment of airway inflammations with minimal systemic side effects [109]. $\Delta^{9}$-Tetrahydrocannabinol solid dispersion was formulated using inulin in a mixture of tertiary butanol and water by spray freeze drying technique. Prepared formulation contains highly porous particles with specific surface area of $90 \mathrm{~m}^{2} / \mathrm{g}$. In vitro deposition of the powder formulations was determined with MSLI at flow rate of $60 \mathrm{~L} / \mathrm{min}$ for $3 \mathrm{sec}$. FPF was found to be $50 \%$ for prepared formulation [110].

2.5. Thin Film Freezing. The particle engineering process, thin film freezing (TFF), has ability to produce low density pharmaceutical powders with a porous, matrix structure. In $\mathrm{TFH}$, the particle morphology can be controlled by influencing the fluid dynamics and heat transfer characteristics upon spreading and freezing of liquid droplets on solid surfaces. When stabilizing excipients with high glass transition temperatures, for instance, PVP or HPMC, are incorporated in the formulation, the pharmaceutical powders can be turned into amorphous ones. These low density TFF developed powders have also been shown to be highly respirable when aerosolized with a marketed inhaler [111, 112].

Microstructured crystalline voriconazole (VRC) and nanostructured amorphous TFF-VRC particles [PVP K25 $(1: 3)$ ] were formulated using thin film freezing technique. The prepared microstructured crystalline VRC and nanostructured amorphous VRC particles showed particle size of $0.45 \mu \mathrm{m}$ and $0.05 \mu \mathrm{m}$, respectively. Powder dispersion was examined using NGI with single dose capsule based HandiHaler device operating at a flow rate of $60 \mathrm{~L} / \mathrm{min}$. NGI analysis showed better dispersion and deposition pattern for microstructured crystalline VRC (\% FPF 37.80) compared to nanostructured amorphous VRC (\% FPF: 32.40) particles. Microstructured crystalline VRC particles also showed approximately $\sim 2$-fold improvement in \% FPF in comparison to micronized VRC with InhaLac ${ }^{\circledR} 70(2 \% \mathrm{w} / \mathrm{w})$. Moreover, in single dose $24 \mathrm{~h}$ pharmacokinetic studies $(10 \mathrm{mg} / \mathrm{kg})$ microstructured crystalline VRC particles showed 2.06fold improvement in $\mathrm{AUC}_{(0-24 \mathrm{~h})}$ of plasma compared to nanostructured amorphous VRC particles [111]. Similarly, an amorphous dry powder of tacrolimus (TAC) was prepared using thin film freezing technique. Aerosol dispersion of TFFprocessed powder was performed using Miat ${ }^{\circledR}$ monodose inhaler device. TFF-processed TAC dry powder showed FPF and MMAD of $83.30 \%$ and $2.26 \mu \mathrm{m}$ respectively. Although being of relatively large geometric size, the TFF-processed dry powder was capable of attaining deep lung due to its low density, highly porous, and brittle characteristics compared to a crystalline micronized TAC powder produced by milling technique. Additionally, in single dose $24 \mathrm{~h}$ pharmacokinetic study, TFF-processed powder showed better pulmonary bioavailability with prolonged retention time compared to a crystalline micronized TAC [112].

\section{Protein, Peptides, and Vaccine Delivery}

Numerous therapeutic proteins and peptides have been used for long time in routine clinical practice. These include insulin, human growth hormone (hGH), calcitonin, and parathyroid for treatment of diabetes, hormone deficiency, and osteoporosis, respectively. Due to recent advance in biochemical sciences and in the knowing of the physiopathology of many disorders, therapeutic biomolecules are likely to become of increasing significance. Pulmonary delivery of these proteins and peptides could compose an alternative to systemic delivery. In fact, direct administration to the lungs 
for local action allows high doses of protein and peptides to be distributed while preventing systemic adverse effects [113]. Another budding use of inhaled proteins and peptides is vaccination, as most antigens are macromolecules. Parenteral drug delivery is usually helpful in preventing systemic infections, but it fails to avoid the early interaction of pathogen and host and continual colonization at the mucosal surface. Mucosal immunization is the local and direct release of antigen to a mucosal surface to stimulate specific immunity versus an attacking pathogen. It has the ability to eradicate many of the difficulties linked with parenteral vaccinations [114]. For example, influenza vaccines have been shown in various animal models to induce appreciably superior mucosal antibody titres when served directly to the pulmonary region, equated with s.c. or i.m. injection [115, 116]. Additionally, pulmonary release can be utilized to offer systemic action of some proteins and peptides. Due to the high surface area of the lungs, the thin layer of the alveolar epithelium, and the high degree of lung vascularization, pulmonary delivery can present fast systemic absorption while ignoring the degradation mechanisms of the hepatic first-pass metabolism and gastrointestinal tract. Apart from this, pulmonary delivery offers advantages over injection in terms of both formulation and delivery technology, that is, patients' acceptance (needlefree delivery) and ease of administration [117].

However, delivery of proteins and peptides to the lungs presents some challenges. A prime issue with inhaled drugs is the necessity to provide the drug as microparticles $(1-5 \mu \mathrm{m})$ to reach the lungs. Secondary question, which is specific to inhaled proteins and peptides, is that they can suffer physicochemical degradation. Physicochemical degradation can also happen during handing out of the proteins and peptides due to diverse stresses, such as exposure to extreme $\mathrm{pH}$ and temperatures. These physicochemical degradations can lead to loss of therapeutic activity. Another concern with these biomolecules is that they are prone to in vivo biological degradation due to the presence of enzymes (i.e., proteases) in the lungs and assorted clearance in the pulmonary area and the blood $[95,118]$. To circumvent these issues, different strategies have been tried and tested for pulmonary applied proteins and peptides. An overview of these strategies along with their key achievements is denoted in Table 6.

\section{Miscellaneous}

Theophylline (THF) cocrystals DPI was prepared using various conformers like urea, saccharin, and nicotinamide by spray drying method. Aerosol dispersion was examined using NGI with Aerolizer inhaler device operating at a flow rate of $60 \mathrm{~L} / \mathrm{min}$ for $6 \mathrm{sec}$. THF nicotinamide cocrystals show better aerosolization performance in comparison to other cocrystals. Micromeritic properties of THF cocrystals play important role in terms of the aerosol performance [119]. Voriconazole loaded large porous particles (VLPP) were prepared from polylactide polymer for treatment of invasive pulmonary aspergillosis. The optimized VLPP exhibited 4.85 $\pm 0.39 \%$ loading efficiency and $0.17 \pm 0.02$ porosity. Aerosol performance was examined using ACI. MMAD and FPF of optimized batch were found to be $2.85 \pm 0.38 \mu \mathrm{m}$ and
$27.3 \pm 2.7 \%$, respectively. VLPP was shown to sustain the release of voriconazole for over 7 days with prolonging the residence time of VRZ at the site of action. Moreover, VLPP does not show any cytotoxic and inflammatory (IL-8) effect over A549 cells [120]. Methotrexate microspheres were fabricated using porous poly-L-lactide (MTX-PLLA-PMs) by emulsion combined precipitation of compressed $\mathrm{CO}_{2}$ antisolvent method. Prepared MTX-PLLA-PMs demonstrated a porous and uneven morphology with $81.6 \%$ of encapsulation efficiency. Additionally, obtained microspheres exhibited 79$85 \%$ porosity, $0.4 \mathrm{~g} \mathrm{~cm}^{-3}$ density, $10-25 \mu \mathrm{m}$ geometric mean diameter, and FPF of $58-62 \%$. Moreover, in in vitro antitumor assay MTX-PLLA-PMs possessed a sustained and better inhibitory activity compared with the neat MTX [121]. Inhalable dry powder composed of crystalline rifapentine and amorphous verapamil in presence of l-leucine was formed by spray drying method. When the dry powder was dispersed by an Osmohaler ${ }^{\circledR}$, the total FPF of rifapentine and verapamil was $71.5 \pm 2.0 \%$ and $77.4 \pm 1.1 \%$, respectively. Notably, the combination resulted in increased killing of $M$. tuberculosis H37Ra with acceptable $\mathrm{IC}_{50}$ values $(62.5 \mu \mathrm{g} / \mathrm{mL})$ on both lung alveolar basal epithelial (A549) and human monocytic (THP1) cell lines. Furthermore, the dry powder was stable after three-month period in $0 \% \mathrm{RH}$ at $20 \pm 3^{\circ} \mathrm{C}$ [122].

\section{Challenges and Future Perspectives}

The successful delivery of any therapeutic agent to the pulmonary region via a DPI depends on four mutually dependent parameters: the formulation, the metering system, the inhaler device, and the patient's understanding/training. This review describes in detail the novel formulation aspects of DPI and merely touched other parameters. But there is an evenly appealing detailed story to be told regarding the inhaler devices, metering system, and patient's understanding/training. Various advantages and challenges in novel respiratory application are given in Figure 1.

Cochleates, a new type of lipid based drug delivery system, are applicable for administration through various routes and can be formulated in powder form. The interior of a cochleate structure remains considerably intact irrespective of outer enzymatic conditions. They have been reported to improve the systemic bioavailability and safety with good level of patient compliance compared to liposomes. There is a need to develop cochleates based dry powder inhaler formulations [70]. Ligand conjugated delivery system can also be explored to enhance the efficacy of the dry powder inhaler. This targeted multifunctional approach not only enhances bioavailability but also helps to deliver therapeutic agents exclusively to the diseased cells in the lungs collectively with suppressors of their resistance to the therapy. Research efforts in this segment led to developed ligand conjugated based dry powder inhaler with better targeting approach.

The growth in NDDS has already boosted the use of DPI for a variety of therapeutic aliments. A lot of novel drug delivery systems have been employed to increase the efficacy of DPI. Still, novel polymer synthesis, use of functionalized carriers, evolution in particle engineering, 


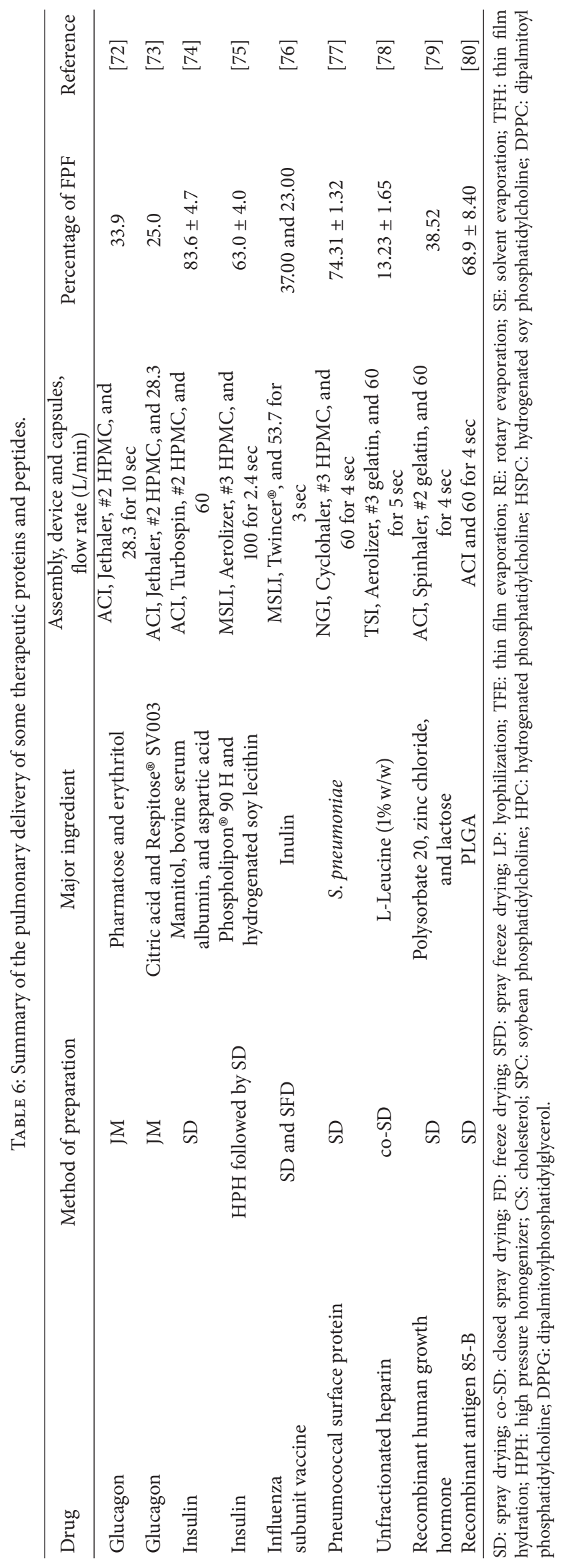




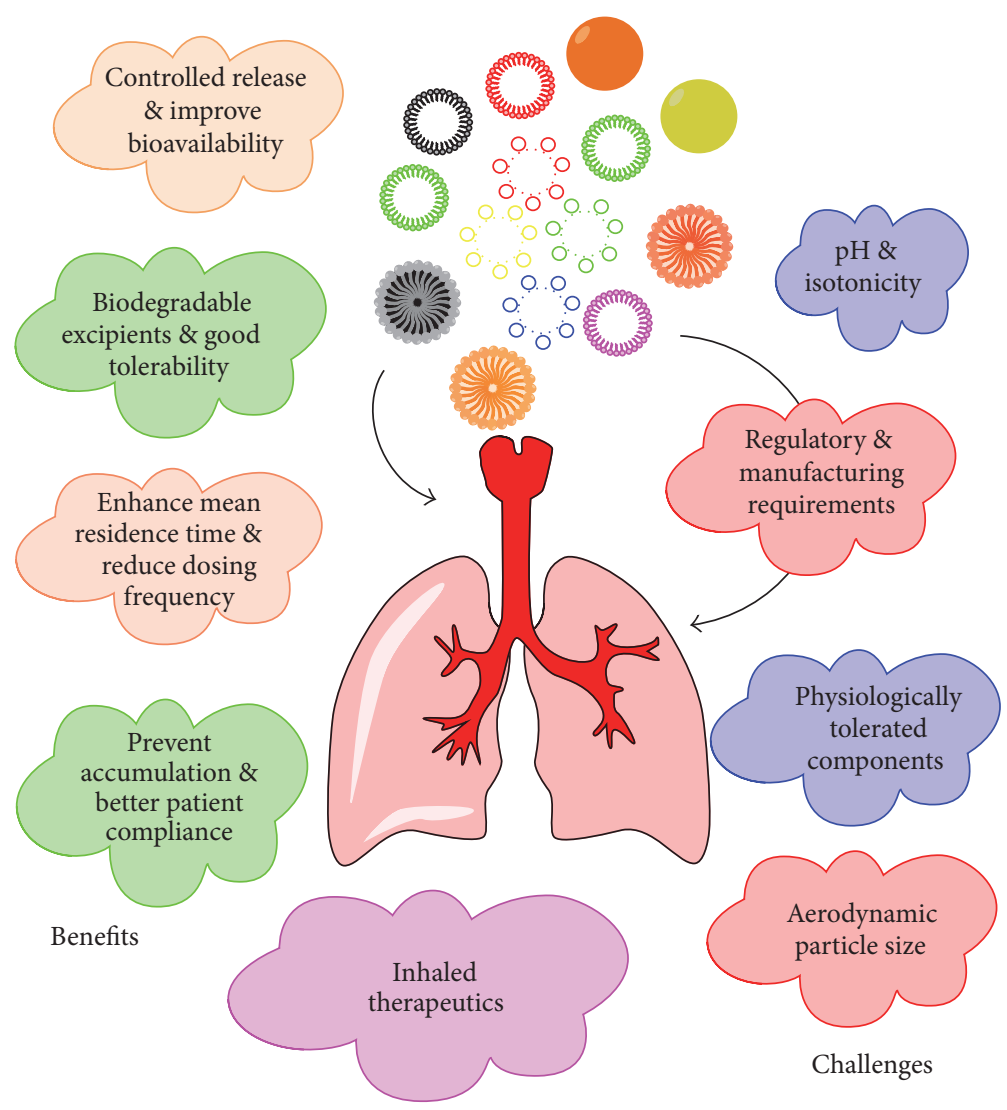

FIGURE 1: Advantages and challenges in novel respiratory drug deliveries.

and better knowledge of the structure function association have to be utilized to facilitate targeting of particles to predetermined lung cells. This may be tested by upholding of their structural integrity, biocompatibility, better stability in pulmonary fluids and enzymes, targeting ability, ease and safety of production, and regulatory requirements. For better localized targeting, ligand based drug delivery seems to have lot of prospect to reach the clinic in the near future. Ethosomes, cubosomes, and other vesicles as carrier systems are better alternative to extend the potential of DPI. Deposition efficiency, systemic toxicity, unfavorable PK/PD profile, and rapid lung clearance like critical issues can be defeated by improving the encapsulation efficiency and use of long circulating carriers. As detailed herein, there are a number of promising novel drug delivery options presently in the developmental pipeline, and if found to be safe, they will be valuable therapeutic alternative for clinicians to improve the end result and survival rates of patients with difficult-totreat pulmonary infections.

\section{Competing Interests}

The author declares that there are no competing interests regarding the publication of this paper.

\section{References}

[1] J. Winkler, G. Hochhaus, and H. Derendorf, "How the lung handles drugs: pharmacokinetics and pharmacodynamics of inhaled corticosteroids," Proceedings of the American Thoracic Society, vol. 1, pp. 356-363, 2004.

[2] M. K. Al-Hallak, M. K. Sarfraz, S. Azarmi, W. H. Roa, W. H. Finlay, and R. Löbenberg, "Pulmonary delivery of inhalable nanoparticles: dry powder inhalers," Therapeutic Delivery, vol. 2, no. 10, pp. 1313-1324, 2011.

[3] A. M. Healy, M. I. Amaro, K. J. Paluch, and L. Tajber, "Dry powders for oral inhalation free of lactose carrier particles," Advanced Drug Delivery Reviews, vol. 75, pp. 32-52, 2014.

[4] M. Hoppentocht, P. Hagedoorn, H. W. Frijlink, and A. H. de Boer, "Technological and practical challenges of dry powder inhalers and formulations," Advanced Drug Delivery Reviews, vol. 75, pp. 18-31, 2014.

[5] X. Liu and G. Huang, "Formation strategies, mechanism of intracellular delivery and potential clinical applications of $\mathrm{pH}$ sensitive liposomes," Asian Journal of Pharmaceutical Sciences, vol. 8, no. 6, pp. 319-328, 2013.

[6] A. Akbarzadeh, R. Rezaei-Sadabady, S. Davaran et al., "Liposome: classification, preparation, and applications," Nanoscale Research Letters, vol. 8, article 102, 2013.

[7] J. P. Clancy, L. Dupont, M. W. Konstan et al., "Phase II studies of nebulised arikace in CF patients with Pseudomonas aeruginosa infection," Thorax, vol. 68, no. 9, pp. 818-825, 2013. 
[8] J. Sinha, S. Mukhopadhyay, N. Das, and M. Basu, "Targeting of liposomal andrographolide to L. donovani infected macrophages in vivo," Drug Delivery, vol. 7, no. 4, pp. 209-213, 2000.

[9] S. P. Shah and A. Misra, "Liposomal amikacin dry powder inhaler: effect of fines on in vitro performance," AAPS PharmSciTech, vol. 5, no. 4, pp. 1-7, 2004.

[10] M. R. Joshi and A. Misra, "Liposomal budesonide for dry powder inhaler: preparation and stabilization," AAPS PharmSciTech, vol. 2, no. 4, pp. 1-10, 2001.

[11] M. Chougule, B. Padhi, and A. Misra, "Development of spray dried liposomal dry powder inhaler of dapsone," AAPS PharmSciTech, vol. 9, no. 1, pp. 47-53, 2008.

[12] M. Gandhi, T. Pandya, R. Gandhi et al., "Inhalable liposomal dry powder of gemcitabine- $\mathrm{HCl}$ : formulation, in vitro characterization and in vivo studies," International Journal of Pharmaceutics, vol. 496, no. 2, pp. 886-895, 2015.

[13] M. Joshi and A. Misra, "Dry powder inhalation of liposomal Ketotifen fumarate: formulation and characterization," International Journal of Pharmaceutics, vol. 223, no. 1-2, pp. 15-27, 2001.

[14] A. F. Ourique, P. D. S. Chaves, G. D. Souto, A. R. Pohlmann, S. S. Guterres, and R. C. R. Beck, "Redispersible liposomal$\mathrm{N}$-acetylcysteine powder for pulmonary administration: development, in vitro characterization and antioxidant activity," European Journal of Pharmaceutical Sciences, vol. 65, pp. 174$182,2014$.

[15] A. Gibbons, N. G. McElvaney, and S.-A. Cryan, "A dry powder formulation of liposome-encapsulated recombinant secretory leukocyte protease inhibitor (rSLPI) for inhalation: preparation and characterisation," AAPS PharmSciTech, vol. 11, no. 3, pp. 1411-1421, 2010.

[16] M. L. Manca, D. Valenti, O. D. Sales, A. Nacher, A. M. Fadda, and M. Manconi, "Fabrication of polyelectrolyte multilayered vesicles as inhalable dry powder for lung administration of rifampicin," International Journal of Pharmaceutics, vol. 472, no. 1-2, pp. 102-109, 2014.

[17] W.-H. Huang, Z.-J. Yang, H. Wu, Y.-F. Wong, Z.-Z. Zhao, and L. Liu, "Development of liposomal salbutamol sulfate dry powder inhaler formulation," Biological and Pharmaceutical Bulletin, vol. 33, no. 3, pp. 512-517, 2010.

[18] M. B. Chougule, B. K. Padhi, and A. Misra, "Nano-liposomal dry powder inhaler of amiloride hydrochloride," Journal of Nanoscience and Nanotechnology, vol. 6, no. 9-10, pp. 3001-3009, 2006.

[19] M. Chougule, B. Padhi, and A. Misra, "Nano-liposomal dry powder inhaler of tacrolimus: preparation, characterization, and pulmonary pharmacokinetics," International Journal of Nanomedicine, vol. 2, no. 4, pp. 675-688, 2007.

[20] W. Rojanarat, N. Changsan, E. Tawithong, S. Pinsuwan, H.K. Chan, and T. Srichana, "Isoniazid pro-liposome powders for inhalation-preparation, characterization and cell culture studies," International Journal of Molecular Sciences, vol. 12, no. 7, pp. 4414-4434, 2011.

[21] A. Patil-Gadhe and V. Pokharkar, "Single step spray drying method to develop proliposomes for inhalation: a systematic study based on quality by design approach," Pulmonary Pharmacology \& Therapeutics, vol. 27, no. 2, pp. 197-207, 2014.

[22] O. B. Garbuzenko, G. Mainelis, O. Taratula, and T. Minko, "Inhalation treatment of lung cancer: the influence of composition, size and shape of nanocarriers on their lung accumulation and retention," Cancer Biology and Medicine, vol. 11, no. 1, pp. 44-55, 2014.
[23] K. M. G. Taylor and J. M. Newton, "Liposomes for controlled delivery of drugs to the lung," Thorax, vol. 47, no. 4, pp. 257259, 1992.

[24] V. Shah, O. Taratula, O. B. Garbuzenko et al., "Genotoxicity of different nanocarriers: possible modifications for the delivery of nucleic acids," Current Drug Discovery Technologies, vol. 10, no. 1, pp. 8-15, 2013.

[25] A. A. Abdelbary, A. M. Al-Mahallawi, M. E. Abdelrahim, and A. M. A. Ali, "Preparation, optimization, and in vitro simulated inhalation delivery of carvedilol nanoparticles loaded on a coarse carrier intended for pulmonary administration," International Journal of Nanomedicine, vol. 10, pp. 6339-6353, 2015.

[26] N. Kumar, S. Soni, A. Jaimini, F. J. Ahmad, A. Bhatnagar, and G. Mittal, "Edetate calcium disodium nanoparticle dry powder inhalation: a novel approach against heavy metal decorporation," International Journal of Pharmaceutics, vol. 416, no. 1, pp. 376-383, 2011.

[27] C. Sinsuebpol, J. Chatchawalsaisin, and P. Kulvanich, "Preparation and in vivo absorption evaluation of spray dried powders containing salmon calcitonin loaded chitosan nanoparticles for pulmonary delivery," Drug Design, Development and Therapy, vol. 7, pp. 861-873, 2013.

[28] N. El-Gendy, E. M. Gorman, E. J. Munson, and C. Berkland, "Budesonide nanoparticle agglomerates as dry powder aerosols with rapid dissolution," Journal of Pharmaceutical Sciences, vol. 98, no. 8, pp. 2731-2746, 2009.

[29] K. Kho and K. Hadinoto, "Optimizing aerosolization efficiency of dry-powder aggregates of thermally-sensitive polymeric nanoparticles produced by spray-freeze-drying," Powder Technology, vol. 214, no. 1, pp. 169-176, 2011.

[30] N. El-Gendy, W. Pornputtapitak, and C. Berkland, "Nanoparticle agglomerates of fluticasone propionate in combination with albuterol sulfate as dry powder aerosols," European Journal of Pharmaceutical Sciences, vol. 44, no. 4, pp. 522-533, 2011.

[31] H. Salem, M. Abdelrahim, K. A. Eid, and M. Sharaf, "Nanosized rods agglomerates as a new approach for formulation of a dry powder inhaler," International Journal of Nanomedicine, vol. 6, pp. 311-320, 2011.

[32] X. Li, F. G. Vogt, D. Hayes Jr., and H. M. Mansour, "Physicochemical characterization and aerosol dispersion performance of organic solution advanced spray-dried microparticulate/nanoparticulate antibiotic dry powders of tobramycin and azithromycin for pulmonary inhalation aerosol delivery," European Journal of Pharmaceutical Sciences, vol. 52, no. 1, pp. 191-205, 2014.

[33] S. Meenach, K. Anderson, J. Hilt, R. McGarry, and H. Mansour, "High performing dry powder inhalers of paclitaxel DPPC/DPPG lung surfactant-mimic multifunctional particles in lung cancer: physicochemical characterization, in vitro aerosol dispersion, and cellular studies," AAPS PharmSciTech, vol. 15, no. 6, pp. 1574-1587, 2014.

[34] S. A. Meenach, K. W. Anderson, J. Zach Hilt, R. C. McGarry, and H. M. Mansour, "Characterization and aerosol dispersion performance of advanced spray-dried chemotherapeutic PEGylated phospholipid particles for dry powder inhalation delivery in lung cancer," European Journal of Pharmaceutical Sciences, vol. 49, no. 4, pp. 699-711, 2013.

[35] F. Ungaro, I. d’Angelo, C. Coletta et al., "Dry powders based on PLGA nanoparticles for pulmonary delivery of antibiotics: modulation of encapsulation efficiency, release rate and lung deposition pattern by hydrophilic polymers," Journal of Controlled Release, vol. 157, no. 1, pp. 149-159, 2012. 
[36] J. Hu, Y. Dong, G. Pastorin, W. K. Ng, and R. B. H. Tan, "Spherical agglomerates of pure drug nanoparticles for improved pulmonary delivery in dry powder inhalers," Journal of Nanoparticle Research, vol. 15, no. 4, article 1560, 2013.

[37] V. Nekkanti, N. Venkatesan, and G. V. Betageri, "Proliposomes for oral delivery: progress and challenges," Current Pharmaceutical Biotechnology, vol. 16, no. 4, pp. 303-312, 2015.

[38] C. Chu, S.-S. Tong, Y. Xu et al., "Proliposomes for oral delivery of dehydrosilymarin: preparation and evaluation in vitro and in vivo," Acta Pharmacologica Sinica, vol. 32, no. 7, pp. 973-980, 2011.

[39] Y.-Z. Li, X. Sun, T. Gong, J. Liu, J. Zuo, and Z.-R. Zhang, "Inhalable microparticles as carriers for pulmonary delivery of thymopentin-loaded solid lipid nanoparticles," Pharmaceutical Research, vol. 27, no. 9, pp. 1977-1986, 2010.

[40] A. Patil-Gadhe, A. Kyadarkunte, M. Patole, and V. Pokharkar, "Montelukast-loaded nanostructured lipid carriers: part II pulmonary drug delivery and in vitro-in vivo aerosol performance," European Journal of Pharmaceutics and Biopharmaceutics, vol. 88, no. 1, pp. 169-177, 2014.

[41] A. Patil-Gadhe and V. Pokharkar, "Pulmonary targeting potential of rosuvastatin loaded nanostructured lipid carrier: optimization by factorial design," International Journal of Pharmaceutics, vol. 501, no. 1-2, pp. 199-210, 2016.

[42] T. Dudala, P. Yalavarthi, H. Vadlamudi, J. Thanniru, G. Yaga, and N. Mudumala, "A perspective overview on lipospheres as lipid carrier systems," International Journal of Pharmaceutical Investigation, vol. 4, no. 4, pp. 149-155, 2014.

[43] S. Naikwade and A. Bajaj, "Preparation and in vitro evaluation of budesonide spray dried microparticles for pulmonary delivery," Scientia Pharmaceutica, vol. 77, no. 2, pp. 419-441, 2009.

[44] H. Adi, P. M. Young, H.-K. Chan, H. Agus, and D. Traini, "Cospray-dried mannitol-ciprofloxacin dry powder inhaler formulation for cystic fibrosis and chronic obstructive pulmonary disease," European Journal of Pharmaceutical Sciences, vol. 40, no. 3, pp. 239-247, 2010.

[45] T. Niwa, D. Mizutani, and K. Danjo, "Spray freeze-dried porous microparticles of a poorly water-soluble drug for respiratory delivery," Chemical and Pharmaceutical Bulletin, vol. 60, no. 7, pp. 870-876, 2012.

[46] M. C. Fontana, T. L. Durli, A. R. Pohlmann, S. S. Guterres, and R. C. R. Beck, "Polymeric controlled release inhalable powder produced by vibrational spray-drying: one-step preparation and in vitro lung deposition," Powder Technology, vol. 258, pp. 4959, 2014.

[47] F. Sansone, R. P. Aquino, P. D. Gaudio, P. Colombo, and P. Russo, "Physical characteristics and aerosol performance of naringin dry powders for pulmonary delivery prepared by spray-drying," European Journal of Pharmaceutics and Biopharmaceutics, vol. 72, no. 1, pp. 206-213, 2009.

[48] A. Kundawala, V. Patel, H. Patel, and D. Choudhary, “Treating tuberculosis with chitosan microparticles loaded with rifampicin as respirable powder for pulmonary delivery," Indian Journal of Novel Drug Delivery, vol. 4, pp. 57-65, 2012.

[49] M. V. Vadakkan, S. S. Binil Raj, C. C. Kartha, and G. S. Vinod Kumar, "Cationic, amphiphilic dextran nanomicellar clusters as an excipient for dry powder inhaler formulation," Acta Biomaterialia, vol. 23, pp. 172-188, 2015.

[50] M. A. Darbandi, N. A. Rouholamini, K. Gilani, and H. Tajerzadeh, "The effect of vehicles on spray drying of rifampicin inhalable microparticles: in vitro and in vivo evaluation," $D A R U$
Journal of Pharmaceutical Sciences, vol. 16, no. 3, pp. 128-135, 2008.

[51] J.-J. Yang, C.-Y. Liu, L.-H. Quan, and Y.-H. Liao, "Preparation and in vitro aerosol performance of spray-dried ShuangHuang-Lian corrugated particles in carrier-based dry powder inhalers," AAPS PharmSciTech, vol. 13, no. 3, pp. 816-825, 2012.

[52] T. P. Learoyd, J. L. Burrows, E. French, and P. C. Seville, "Sustained delivery by leucine-modified chitosan spray-dried respirable powders," International Journal of Pharmaceutics, vol. 372, no. 1-2, pp. 97-104, 2009.

[53] S. Arora, M. Haghi, C.-Y. Loo, D. Traini, P. M. Young, and S. Jain, "Development of an inhaled controlled release voriconazole dry powder formulation for the treatment of respiratory fungal infection," Molecular Pharmaceutics, vol. 12, no. 6, pp. 20012009, 2015.

[54] Z. Daman, K. Gilani, A. Rouholamini Najafabadi, H. R. Eftekhari, and M. A. Barghi, "Formulation of inhalable lipidbased salbutamol sulfate microparticles by spray drying technique," DARU, Journal of Pharmaceutical Sciences, vol. 22, no. 1, article 50, 2014.

[55] S. Scalia, M. Haghi, V. Losi, V. Trotta, P. M. Young, and D. Traini, "Quercetin solid lipid microparticles: a flavonoid for inhalation lung delivery," European Journal of Pharmaceutical Sciences, vol. 49, no. 2, pp. 278-285, 2013.

[56] M. Mezzena, S. Scalia, P. M. Young, and D. Traini, "Solid lipid budesonide microparticles for controlled release inhalation therapy," The AAPS Journal, vol. 11, no. 4, pp. 771-778, 2009.

[57] A. Kuzmov and T. Minko, "Nanotechnology approaches for inhalation treatment of lung diseases," Journal of Controlled Release, vol. 219, pp. 500-518, 2015.

[58] A. J. Mali, A. P. Pawar, and R. N. Purohit, "Development of budesonide loaded biopolymer based dry powder inhaler: optimization, in vitro deposition, and cytotoxicity study," Journal of Pharmaceutics, vol. 2014, Article ID 795371, 12 pages, 2014.

[59] L.-M. Xu, Q.-X. Zhang, Y. Zhou, H. Zhao, J.-X. Wang, and J.-F. Chen, "Engineering drug ultrafine particles of beclomethasone dipropionate for dry powder inhalation," International Journal of Pharmaceutics, vol. 436, no. 1-2, pp. 1-9, 2012.

[60] R. S. Dhumal, S. V. Biradar, A. R. Paradkar, and P. York, "Particle engineering using sonocrystallization: salbutamol sulphate for pulmonary delivery," International Journal of Pharmaceutics, vol. 368, no. 1-2, pp. 129-137, 2009.

[61] Q. Zhou, L. Qu, T. Gengenbach, I. Larson, P. J. Stewart, and D. A. V. Morton, "Effect of surface coating with magnesium stearate via mechanical dry powder coating approach on the aerosol performance of micronized drug powders from dry powder inhalers," AAPS PharmSciTech, vol. 14, no. 1, pp. 38-44, 2013.

[62] N. R. Rabbani and P. C. Seville, "The influence of formulation components on the aerosolisation properties of spray-dried powders," Journal of Controlled Release, vol. 110, no. 1, pp. 130140, 2005.

[63] X. Wu, W. Zhang, D. Hayes Jr., and H. M. Mansour, "Physicochemical characterization and aerosol dispersion performance of organic solution advanced spray-dried cyclosporine A multifunctional particles for dry powder inhalation aerosol delivery," International Journal of Nanomedicine, vol. 8, pp. 1269-1283, 2013.

[64] C. Singh, L. V. S. K. Koduri, A. Singh, and S. Suresh, "Novel potential for optimization of antitubercular therapy: pulmonary delivery of rifampicin lipospheres," Asian Journal of Pharmaceutical Sciences, vol. 10, no. 6, pp. 549-562, 2015. 
[65] M. C. Gaspar, J. J. S. Sousa, A. A. C. C. Pais et al., "Optimization of levofloxacin-loaded crosslinked chitosan microspheres for inhaled aerosol therapy," European Journal of Pharmaceutics and Biopharmaceutics, vol. 96, pp. 65-75, 2015.

[66] H. S. Mahajan and S. A. Gundare, "Preparation, characterization and pulmonary pharmacokinetics of xyloglucan microspheres as dry powder inhalation," Carbohydrate Polymers, vol. 102, no. 1, pp. 529-536, 2014.

[67] R. Diab, J. Brillault, A. Bardy, A. V. L. Gontijo, and J. C. Olivier, "Formulation and in vitro characterization of inhalable polyvinyl alcohol-free rifampicin-loaded PLGA microspheres prepared with sucrose palmitate as stabilizer: efficiency for ex vivo alveolar macrophage targeting," International Journal of Pharmaceutics, vol. 436, no. 1-2, pp. 833-839, 2012.

[68] R. A. Tuli, T. R. Dargaville, G. A. George, and N. Islam, "Polycaprolactone microspheres as carriers for dry powder inhalers: effect of surface coating on aerosolization of salbutamol sulfate," Journal of Pharmaceutical Sciences, vol. 101, no. 2, pp. 733-745, 2012.

[69] D. J. Singh, A. A. Lohade, J. J. Parmar et al., "Development of chitosan-based dry powder inhalation system of cisplatin for lung cancer," Indian Journal of Pharmaceutical Sciences, vol. 74, no. 6, pp. 521-526, 2012.

[70] A. Pawar, C. Bothiraja, K. Shaikh, and A. Mali, "An insight into cochleates, a potential drug delivery system," RSC Advances, vol. 5, no. 99, pp. 81188-81202, 2015.

[71] G. Pilcer, T. Sebti, and K. Amighi, "Formulation and characterization of lipid-coated tobramycin particles for dry powder inhalation," Pharmaceutical Research, vol. 23, no. 5, pp. 931-940, 2006.

[72] K. Endo, S. Amikawa, A. Matsumoto, N. Sahashi, and S. Onoue, "Erythritol-based dry powder of glucagon for pulmonary administration," International Journal of Pharmaceutics, vol. 290, no. 1-2, pp. 63-71, 2005.

[73] S. Onoue, K. Yamamoto, Y. Kawabata, M. Hirose, T. Mizumoto, and S. Yamada, "Novel dry powder inhaler formulation of glucagon with addition of citric acid for enhanced pulmonary delivery," International Journal of Pharmaceutics, vol. 382, no. 1-2, pp. 144-150, 2009.

[74] A. G. Balducci, S. Cagnani, F. Sonvico et al., "Pure insulin highly respirable powders for inhalation," European Journal of Pharmaceutical Sciences, vol. 51, no. 1, pp. 110-117, 2014.

[75] F. Depreter and K. Amighi, "Formulation and in vitro evaluation of highly dispersive insulin dry powder formulations for lung administration," European Journal of Pharmaceutics and Biopharmaceutics, vol. 76, no. 3, pp. 454-463, 2010.

[76] V. Saluja, J.-P. Amorij, J. C. Kapteyn, A. H. de Boer, H. W. Frijlink, and W. L. J. Hinrichs, "A comparison between spray drying and spray freeze drying to produce an influenza subunit vaccine powder for inhalation," Journal of Controlled Release, vol. 144, no. 2, pp. 127-133, 2010.

[77] N. K. Kunda, I. M. Alfagih, E. N. Miyaji et al., "Pulmonary dry powder vaccine of pneumococcal antigen loaded nanoparticles," International Journal of Pharmaceutics, vol. 495, no. 2, pp. 903-912, 2015.

[78] J. Shur, T. G. Nevell, R. J. Ewen et al., "Cospray-dried unfractionated heparin with l-leucine as a dry powder inhaler mucolytic for cystic fibrosis therapy," Journal of Pharmaceutical Sciences, vol. 97, no. 11, pp. 4857-4868, 2008.

[79] M. Jalalipour, K. Gilani, H. Tajerzadeh, A. R. Najafabadi, and M. Barghi, "Characterization and aerodynamic evaluation of spray dried recombinant human growth hormone using protein stabilizing agents," International Journal of Pharmaceutics, vol. 352, no. 1-2, pp. 209-216, 2008.

[80] D. Lu, L. Garcia-Contreras, P. Muttil et al., "Pulmonary immunization using antigen 85 -b polymeric microparticles to boost tuberculosis immunity," The AAPS Journal, vol. 12, no. 3, pp. 338-347, 2010.

[81] A. Wicki, D. Witzigmann, V. Balasubramanian, and J. Huwyler, "Nanomedicine in cancer therapy: challenges, opportunities, and clinical applications," Journal of Controlled Release, vol. 200, pp. 138-157, 2015.

[82] F. Danhier, E. Ansorena, J. M. Silva, R. Coco, A. Le Breton, and V. Préat, "PLGA-based nanoparticles: an overview of biomedical applications," Journal of Controlled Release, vol. 161, no. 2, pp. 505-522, 2012.

[83] D.-C. Li, X.-K. Zhong, Z.-P. Zeng et al., "Application of targeted drug delivery system in Chinese medicine," Journal of Controlled Release, vol. 138, no. 2, pp. 103-112, 2009.

[84] J. Zhang, L. Wu, H.-K. Chan, and W. Watanabe, "Formation, characterization, and fate of inhaled drug nanoparticles," Advanced Drug Delivery Reviews, vol. 63, no. 6, pp. 441-455, 2011.

[85] N. Tsapis, D. Bennett, B. Jackson, D. A. Weitz, and D. A. Edwards, "Trojan particles: large porous carriers of nanoparticles for drug delivery," Proceedings of the National Academy of Sciences of the United States of America, vol. 99, no. 19, pp. 1200112005, 2002.

[86] W. S. Cheow, M. L. L. Ng, K. Kho, and K. Hadinoto, "Sprayfreeze-drying production of thermally sensitive polymeric nanoparticle aggregates for inhaled drug delivery: effect of freeze-drying adjuvants," International Journal of Pharmaceutics, vol. 404, no. 1-2, pp. 289-300, 2011.

[87] G. Kaptay, "The gibbs equation versus the kelvin and the gibbsthomson equations to describe nucleation and equilibrium of nano-materials," Journal of Nanoscience and Nanotechnology, vol. 12, no. 3, pp. 2625-2633, 2012.

[88] B. E. Rabinow, "Nanosuspensions in drug delivery," Nature Reviews Drug Discovery, vol. 3, no. 9, pp. 785-796, 2004.

[89] W. Yang, J. I. Peters, and R. O. Williams III, "Inhaled nanoparticles-a current review," International Journal of Pharmaceutics, vol. 356, no. 1-2, pp. 239-247, 2008.

[90] J. C. Sung, D. J. Padilla, L. Garcia-Contreras et al., "Formulation and pharmacokinetics of self-assembled rifampicin nanoparticle systems for pulmonary delivery," Pharmaceutical Research, vol. 26, no. 8, pp. 1847-1855, 2009.

[91] Y. Wang, K. Kho, W. S. Cheow, and K. Hadinoto, "A comparison between spray drying and spray freeze drying for dry powder inhaler formulation of drug-loaded lipid-polymer hybrid nanoparticles," International Journal of Pharmaceutics, vol. 424, no. 1-2, pp. 98-106, 2012.

[92] S. M. D’Addio, J. G. Y. Chan, P. C. L. Kwok, B. R. Benson, R. K. Prud'Homme, and H.-K. Chan, "Aerosol delivery of nanoparticles in uniform mannitol carriers formulated by ultrasonic spray freeze drying," Pharmaceutical Research, vol. 30, no. 11, pp. 2891-2901, 2013.

[93] S. M. D’Addio, J. G. Y. Chan, P. C. L. Kwok, R. K. Prud'homme, and H.-K. Chan, "Constant size, variable density aerosol particles by ultrasonic spray freeze drying," International Journal of Pharmaceutics, vol. 427, no. 2, pp. 185-191, 2012.

[94] J. Pardeike, A. Hommoss, and R. H. Müller, "Lipid nanoparticles (SLN, NLC) in cosmetic and pharmaceutical dermal products," International Journal of Pharmaceutics, vol. 366, no. 1-2, pp. 170184, 2009. 
[95] S. Weber, A. Zimmer, and J. Pardeike, "Solid Lipid Nanoparticles (SLN) and Nanostructured Lipid Carriers (NLC) for pulmonary application: a review of the state of the art," European Journal of Pharmaceutics and Biopharmaceutics, vol. 86, no. 1, pp. 7-22, 2014.

[96] A. Pawar, S. Rajalakshmi, P. Mehta, K. Shaikh, and C. Bothiraja, "Strategies for formulation development of andrographolide," RSC Advances, vol. 6, no. 73, pp. 69282-69300, 2016.

[97] W. Mehnert and K. Mäder, "Solid lipid nanoparticles: production, characterization and applications," Advanced Drug Delivery Reviews, vol. 47, no. 2-3, pp. 165-196, 2001.

[98] R. R. Patlolla, M. Chougule, A. R. Patel, T. Jackson, P. N. V. Tata, and M. Singh, "Formulation, characterization and pulmonary deposition of nebulized celecoxib encapsulated nanostructured lipid carriers," Journal of Controlled Release, vol. 144, no. 2, pp. 233-241, 2010.

[99] A. J. Mali, A. P. Pawar, and C. Bothiraja, "Improved lung delivery of budesonide from biopolymer based dry powder inhaler through natural inhalation of rat," Materials Technology, vol. 29, no. 6, pp. 350-357, 2014.

[100] I. S. Chandiran, B. Pavan Kumar, and K. N. Jayaveera, "Design and development of microparticulate drug delivery system of Glimepiride for controlled release," Drug Invention Today, vol. 5, no. 3, pp. 235-240, 2013.

[101] N. K. Varde and D. W. Pack, "Microspheres for controlled release drug delivery," Expert Opinion on Biological Therapy, vol. 4, no. 1, pp. 35-51, 2004.

[102] M. F. Ali and S. Bakalis, "Mucoadhesive polymers for food formulations," Procedia Food Science, vol. 1, pp. 68-75, 2011.

[103] M. Mishra and B. Mishra, "Mucoadhesive microparticles as potential carriers in inhalation delivery of doxycycline hyclate: a comparative study," Acta Pharmaceutica Sinica B, vol. 2, no. 5, pp. 518-526, 2012.

[104] M. Sakagami, W. Kinoshita, K. Sakon, J. Sato, and Y. Makino, "Mucoadhesive beclomethasone microspheres for powder inhalation: Their pharmacokinetics and pharmacodynamics evaluation," Journal of Controlled Release, vol. 80, no. 1-3, pp. 207-218, 2002.

[105] R. Kamble, P. Palve, and P. Mehta, "Preparation and evaluation of amorphous olmesartan medoxomil with porous silica microparticles using spray-drying technique," Journal of Advanced Pharmacy Education \& Research, vol. 4, pp. 65-71, 2014.

[106] C. Bothiraja, M. B. Shinde, S. Rajalakshmi, and A. P. Pawar, "Evaluation of molecular pharmaceutical and in-vivo properties of spray-dried isolated andrographolide-PVP," Journal of Pharmacy and Pharmacology, vol. 61, no. 11, pp. 1465-1472, 2009.

[107] V. Dhapte and P. Mehta, "Advances in hydrotropic solutions: an updated review," St. Petersburg Polytechnical University Journal: Physics and Mathematics, vol. 1, no. 4, pp. 424-435, 2015.

[108] C. Duret, N. Wauthoz, T. Sebti, F. Vanderbist, and K. Amighi, "Solid dispersions of itraconazole for inhalation with enhanced dissolution, solubility and dispersion properties," International Journal of Pharmaceutics, vol. 428, no. 1-2, pp. 103-113, 2012.

[109] S. Onoue, H. Sato, Y. Kawabata, T. Mizumoto, N. Hashimoto, and S. Yamada, "In vitro and in vivo characterization on amorphous solid dispersion of cyclosporine A for inhalation therapy," Journal of Controlled Release, vol. 138, no. 1, pp. 16-23, 2009.

[110] D.-J. Van Drooge, W. L. J. Hinrichs, B. H. J. Dickhoff et al., "Spray freeze drying to produce a stable $\Delta^{9}$-tetrahydrocannabinol containing inulin-based solid dispersion powder suitable for inhalation," European Journal of Pharmaceutical Sciences, vol. 26, no. 2, pp. 231-240, 2005.

[111] N. A. Beinborn, J. Du, N. P. Wiederhold, H. D. C. Smyth, and R. O. Williams III, "Dry powder insufflation of crystalline and amorphous voriconazole formulations produced by thin film freezing to mice," European Journal of Pharmaceutics and Biopharmaceutics, vol. 81, no. 3, pp. 600-608, 2012.

[112] K. A. Overhoff, K. P. Johnston, J. Tam, J. Engstrom, and R. O. Williams III, "Use of thin film freezing to enable drug delivery: a review," Journal of Drug Delivery Science and Technology, vol. 19, no. 2, pp. 89-98, 2009.

[113] Y.-B. Wang, A. B. Watts, J. I. Peters, S. Liu, A. Batra, and R. O. Williams III, "In vitro and in vivo performance of dry powder inhalation formulations: comparison of particles prepared by thin film freezing and micronization," AAPS PharmSciTech, vol. 15, no. 4, pp. 981-993, 2014.

[114] F. Depreter, G. Pilcer, and K. Amighi, "Inhaled proteins: challenges and perspectives," International Journal of Pharmaceutics, vol. 447, no. 1-2, pp. 251-280, 2013.

[115] T. Sou, E. N. Meeusen, M. de Veer, D. A. V. Morton, L. M. Kaminskas, and M. P. McIntosh, "New developments in dry powder pulmonary vaccine delivery," Trends in Biotechnology, vol. 29, no. 4, pp. 191-198, 2011.

[116] J. Wee, J. Scheerlinck, K. Snibson et al., "Pulmonary delivery of iscomatrix influenza vaccine induces both systemic and mucosal immunity with antigen dose sparing," Mucosal Immunology, vol. 1, pp. 489-496, 2008.

[117] J. Huang, R. J. Garmise, T. M. Crowder et al., "A novel dry powder influenza vaccine and intranasal delivery technology: induction of systemic and mucosal immune responses in rats," Vaccine, vol. 23, no. 6, pp. 794-801, 2004.

[118] M. Witting, K. Obst, W. Friess, and S. Hedtrich, "Recent advances in topical delivery of proteins and peptides mediated by soft matter nanocarriers," Biotechnology Advances, vol. 33, no. 6, pp. 1355-1369, 2015.

[119] A. Alhalaweh, W. Kaialy, G. Buckton, H. Gill, A. Nokhodchi, and S. P. Velaga, "Theophylline cocrystals prepared by spray drying: physicochemical properties and aerosolization performance," AAPS PharmSciTech, vol. 14, no. 1, pp. 265-276, 2013.

[120] S. Arora, R. R. Mahajan, V. Kushwah, D. Baradia, A. Misra, and S. Jain, "Development of voriconazole loaded large porous particles for inhalation delivery: effect of surface forces on aerosolisation performance, assessment of in vitro safety potential and uptake by macrophages," RSC Advances, vol. 5, no. 48, pp. 38030-38043, 2015.

[121] A.-Z. Chen, C. Zhao, S.-B. Wang, Y.-G. Liu, and D.-L. Lin, "Generation of porous poly-L-lactide microspheres by emulsioncombined precipitation with a compressed $\mathrm{CO}_{2}$ antisolvent process," Journal of Materials Chemistry B, vol. 1, no. 23, pp. 2967-2975, 2013.

[122] T. Parumasivam, J. G. Chan, A. Pang et al., "In vitro evaluation of inhalable verapamil-rifapentine particles for tuberculosis therapy," Molecular Pharmaceutics, vol. 13, no. 3, pp. 979-989, 2016. 

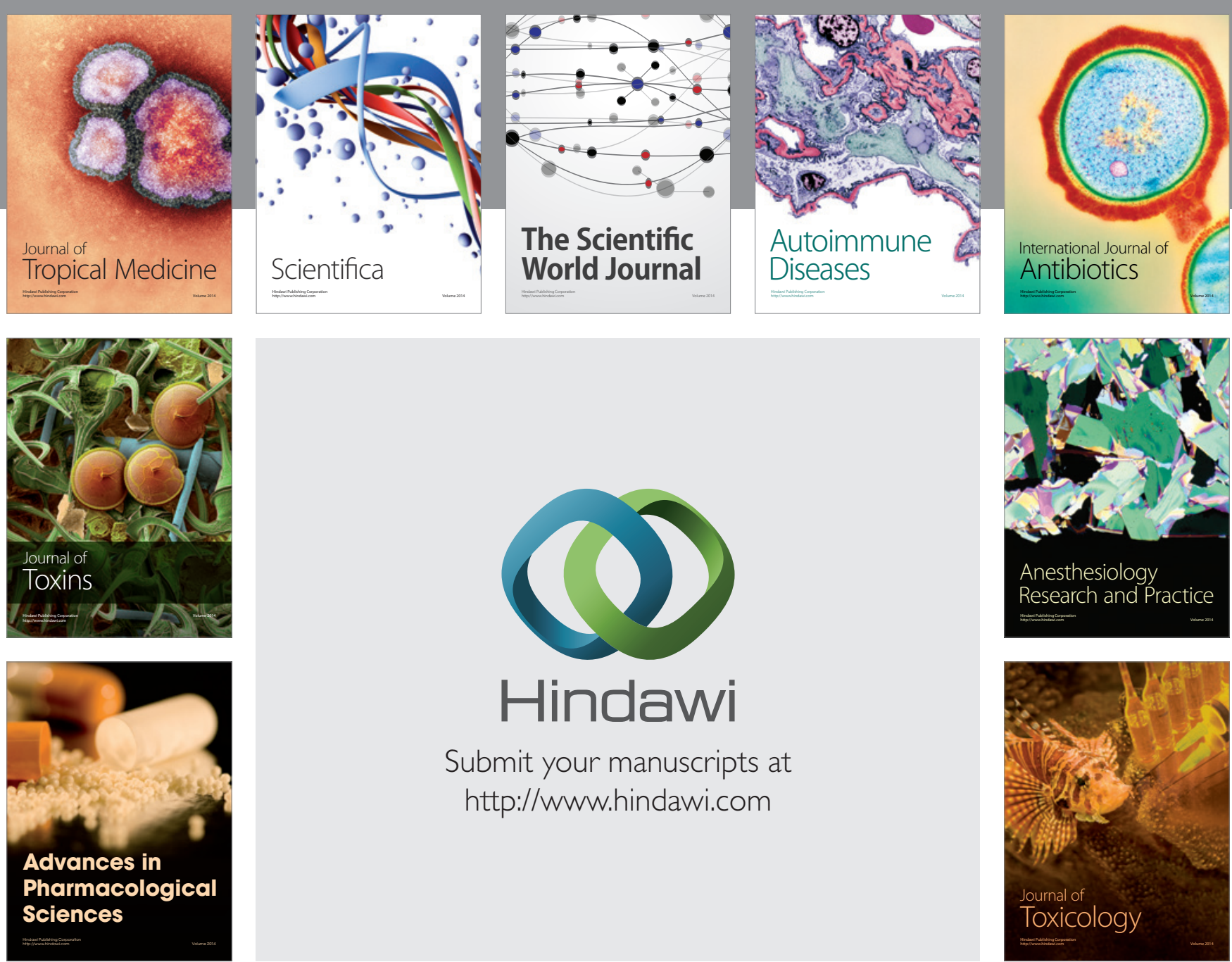

\section{Hindawi}

Submit your manuscripts at

http://www.hindawi.com
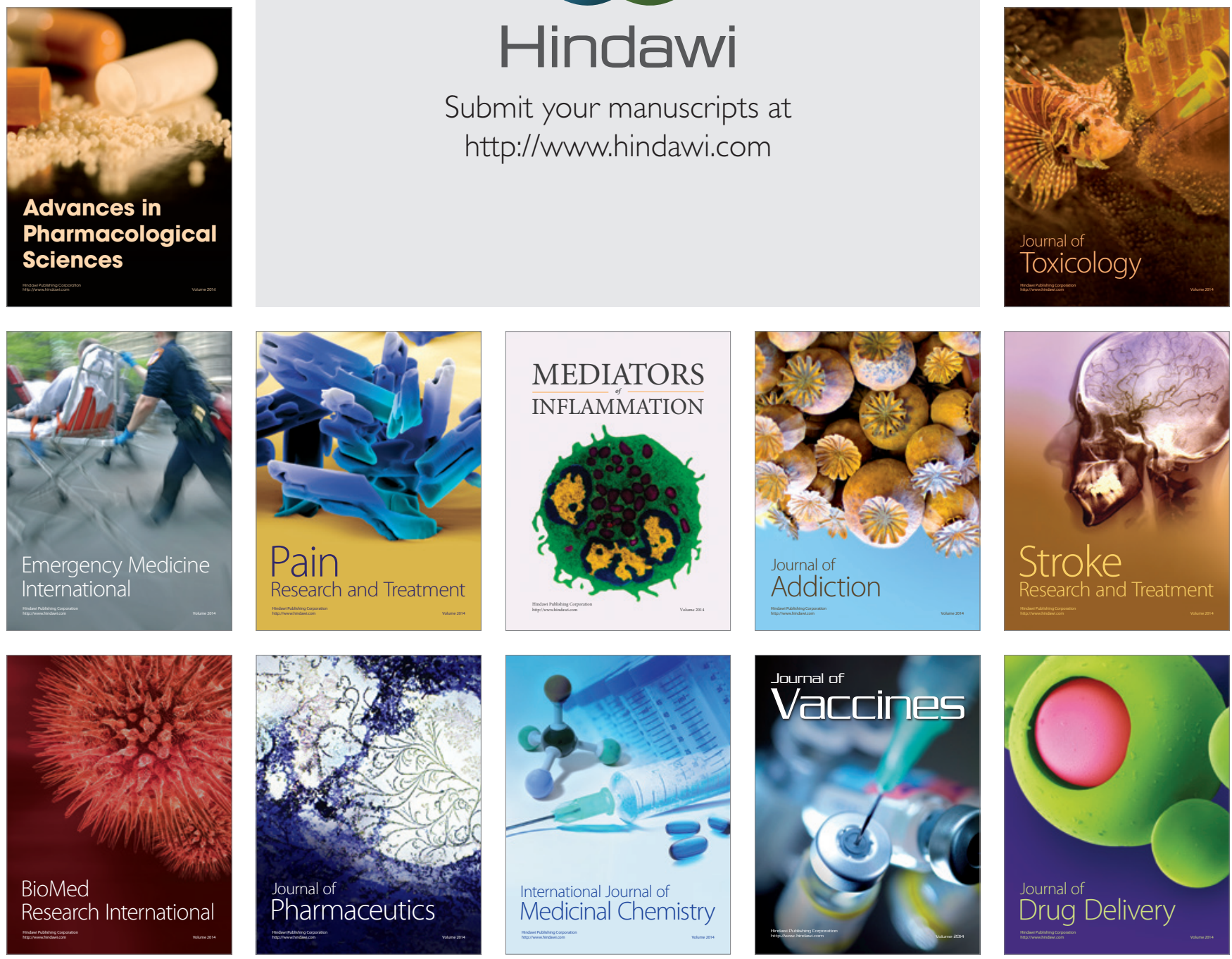